\title{
Schwedische Jowat-Niederlassung mit neuem Managing Director
}

$\mathrm{B}$ ereits seit Februar 2013 ist Christer Ekstrand Managing Director bei der Jowat Scandinavia AB, der schwedischen Niederlassung der Jowat AG mit Sitz in Malmö. Ekstrand war zuvor bei der Lahega Kemi AB als Director Sales \& Marketing tätig und für das internationale Kundenmanagement verantwortlich.

Gemeinsam mit seinem Team widmet sich der 49-Jährige der Umsetzung der Jowat-Branchenstrategie für den schwedischen Markt. Dabei steht die Etablierung der drei Branchenmanagements Holz/Bau/Möbel, Papier/Verpackung und Automobil/Textil/Elektro in Schweden im Fokus. „Unser Ziel ist es, unsere Klebstoffkompetenz branchenübergreifend unter Beweis zu stellen und so als Partner für unsere Kunden zu agieren“, so Ekstrand.

„Wir verfolgen die Strategie der Etablierung unserer Fokusbranchen auch in Skandinavien. Mit Christer Ekstrand haben wir einen kompetenten Ansprechpartner für unsere Kunden gewonnen, der in Skandinavien das breite Cross-Industry-Know-how der Jowat AG in Sachen Klebstoff im Markt platziert“, sagt Klaus Kullmann, Vorstand Marketing und Vertrieb der Jowat AG.

Ihm zur Seite steht Per-Anders Lindgren, der seit 2010 bei der Jowat Scandinavia AB beschäftigt ist und die Branchenverantwortung für das Geschäftsfeld Holz, Bau und Möbel übernimmt.

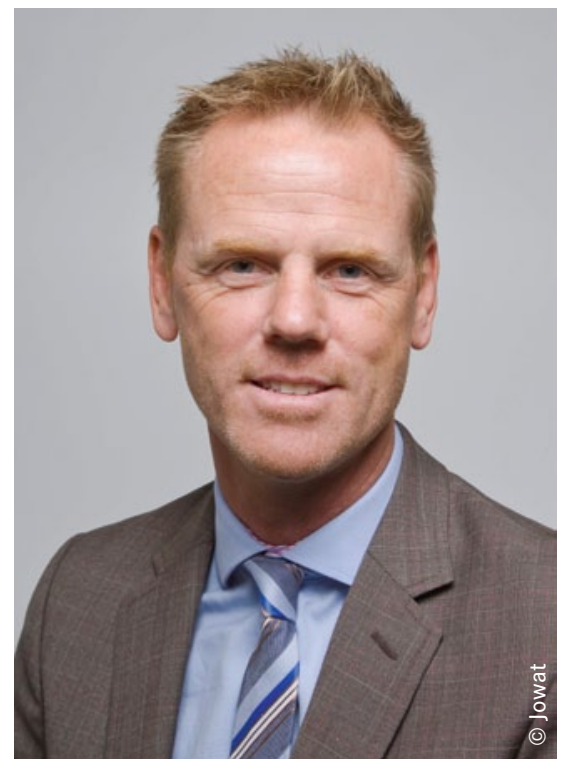

Christer Ekstrand, neuer Managing Director bei der Jowat Scandinavia AB

\section{Wacker eröffnet Technical Center in den USA}

Die Wacker Chemie AG hat ein neues Technical Center für Teppichanwendungen in Dalton (Georgia) in Betrieb genommen. Diese Einrichtung dient als Entwicklungs- und Testlabor für polymere Bindemittel, die in der Teppichindustrie Einsatz finden.

U nser Ziel ist es, die individuellen Anforderungen unserer Kunden aus der Teppichbranche direkt vor Ort umzusetzen und mit ihnen innovative Anwendungen mit Vinylacetat-EthylenCopolymer (VAE)-Dispersionen zu ent- wickeln und zu testen“, erklärt Peter Summo, Leiter des Dispersionsgeschäfts bei Wacker Polymers.

Neben Laborräumen für Forschung und Anwendungstechnik beherbergt die Einrichtung auch eine lokale Nie-

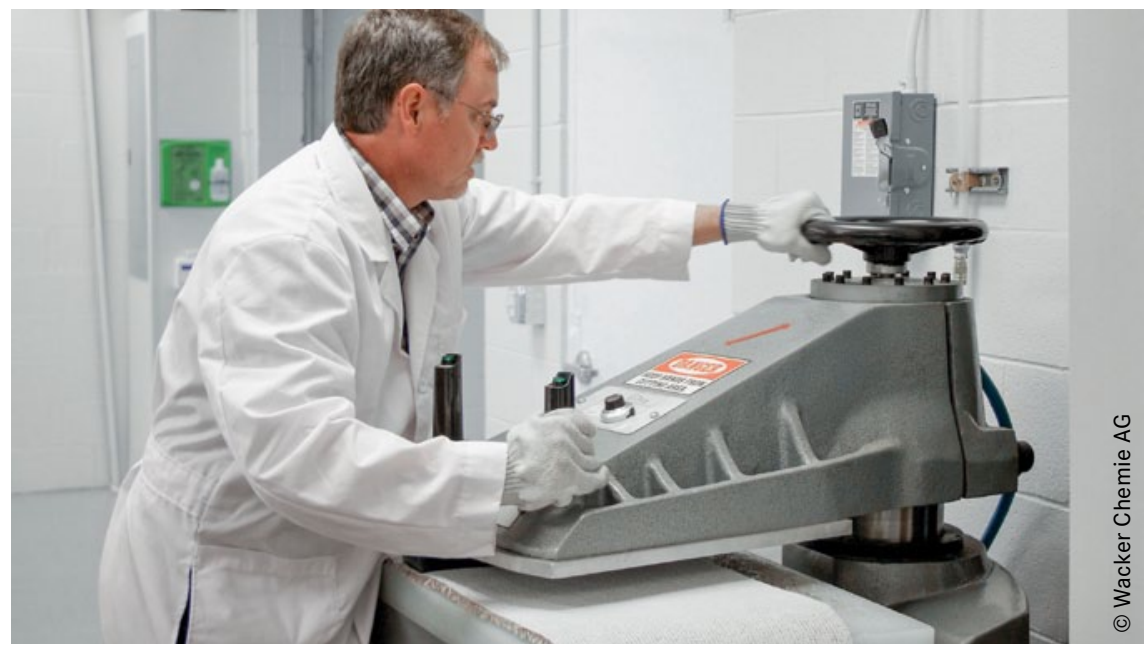

derlassung des firmeneigenen Schulungs- und Fortbildungszentrums Wacker Academy. Das Seminarprogramm ist dabei auf die besonderen Bedürfnisse der Teppichbranche ausgerichtet. Das eigens eingerichtete Trainingslabor ermöglicht den Teilnehmern darüber hinaus umfassende praktische Übungen. Neben den etablierten US-Trainingszentren in Adrian (MI) und Allentown (PA) betreibt der Münchner Chemiekonzern bereits Standorte der Wacker Academy in Burghausen (Deutschland), Moskau (Russland), Beijing (China), Seoul (Südkorea), Mumbai (Indien), Sao Paulo (Brasilien), Singapur, Dubai (V.A.E.) und Mexiko Stadt (Mexiko).

Im neuen Technical Center in Dalton können neue Klebstoffformulierungen mit VAE-Dispersionen für die Teppichindustrie entwickelt und getestet werden. 